\title{
Application of Campus Parking Area for State Polytechnic of Sriwijaya Based on Smartphone
}

\author{
Leni Novianti ${ }^{1, *}$, Devi Sartika ${ }^{1}$ Dewi Irmawati ${ }^{1}$ Ienda Meiriska ${ }^{1}$ \\ ${ }^{1}$ Study Program of Informatics Management, State Polytechnic of Sriwijaya \\ ${ }^{*}$ Corresponding author. Email: leninovianti16@gmail.com
}

\begin{abstract}
The purpose of this study was to improve the services and information on the availability of parking lots so that there would be no hoarding of two-wheeled or four-wheeled vehicles that caused the congestion in the State Polytechnic of Sriwijaya and also to made it easier for the security officers to verify the vehicles. The limitations of this study were focused on the parking space of the State Polytechnic of Sriwijaya based on the smartphone (QR Code). The data processed was the data of both two-wheeled and four-wheeled vehicles. The method used for system development was Prototyping. The resulting output was a smartphone-based application for the State Polytechnic of Sriwijaya parking area (QR Code).
\end{abstract}

Keywords: Parking Area, Smartphone (QR Code), Prototyping

\section{INTRODUCTION}

The vehicle parking area is an indispensable public service facility and an important facility of an institution or company. In many cities, universities with their staff and their student populations account for a significant proportion of the urban population. The provision of transport infrastructure, of which parking facilities form an important component, has been a major responsibility for the university authorities (Filipovitch and Boomah, 2016) under the title A systems model for achieving optimum parking efficiency on campus: The case of Minnesota State University [1] [4]. Given the high number of journeys drawn to university campuses due to their importance as centres of employment, teaching, research and dissemination, many suffer from problems related to mobility. These problems from the overuse of the private car by people trying to get to the campus (dell'olio et al,2016) under the title A methodology based on parking policy to promote sustainable mobility in college campuses [2]. The results in Unlocking the smartphone's sensors for smart city provided information a system that relies on smartphone sensors and the ubiquitous $\mathrm{WiFi} /$ cellular infrastructure to provide real-time parking availability information. SmartPark addresses the challenge of detecting unparking events by solving the automatic transportation mode detection and location matching problems (Krieg et al, 2017).[3]
The parking system applied at the State Polytechnic of Sriwijiya is still manual. People who used vehicle entered the campus area and started to search the parking lots. In the off-peak hours-, there might not be a problem but at peak hours the process of finding a parking space became a problem and required a lot of time and was ineffective because the driver would go around the campus to find an empty parking lot. If people did not get an empty parking lot then the driver would park the vehicle in any place and that caused a hoarding of the vehicles that can create congestion.

\section{DESCRIPTION OF STUDY AREA}

Situation analysis of parking lots at the State Polytechnic of Sriwijaya is when people with their vehicles entered State Polytechnic of Sriwijaya gate, they did not get a ticket /entrance ticket, especially students who drove two-wheeled vehicles that only showed the vehicle registration (motor vehicle registration letter) while for four-wheeled vehicle could entered and exited directly from/to the gate without checking even though the process of recording the entrance and exit of vehicles was very important because the data in and out of the vehicle could be used for reporting in the management of the parking lot making it easier for park officers to monitor vehicles that come in and out and support security towards motorbike robbing that often occurs in the campus environment. With structured and neat 
parking lots it can provide information about the empty parking lots.

With the existing problems and limitations of the parking system now, a digitization application is designed that records the process of entering and exiting the vehicle and providing information on vacant parking lots in the State Polytechnic of Sriwijaya campus environment and the use of Android-based smartphone technology is expected to be an information medium for people to look for an empty parking space in the State Polytechnic of Sriwijaya. Because a smartphone is a gadget that is no longer a luxury item but has become a gadget that all students or the general public have. The current problems are:

1. Management and arrangement of campus parking lots in State Polytechnic of Sriwijaya still use manual methods.

2. Utilization of technology that has not been maximized to improve the information services to vehicle users both students, lecturers or the general public to more easily obtain parking space information in the State Polytechnic of Sriwijaya.

With the problems above, to optimize parking information on the State Polytechnic of Sriwijaya for the users of vehicles which are students, lecturers and the general public is "how to design and build a Parking Application for the State Polytechnic of Sriwijaya Based on Smartphone."

\subsection{Smartphone}

According to the Oxford Dictionaries www.oxforddictionaries.com, the smartphone is "A mobile phone that can perform many of the functions of a computer, typically having a relatively large screen and an operating system capable of running general-purpose applications."

Meanwhile, according to the Business Dictionary (www.businessdictionary.com), the smartphone is "Mobile phone which includes functions similar to those found on personal computers. Smartphones provide a one-stop solution for information management, mobile calls, email sending, and Internet access Smartphones are compact in and often only slightly bigger than standard mobile telephones.

According to some experts, the notion of a smartphone are:

a. David Wood As a Vice President of the Executive of PT Symbian revealed that a smartphone is a type of cellphone that can be distinguished from the usual types of telecommunications equipment, namely how the manufacturing process and the process of doing it.

b. Williams and Sawyer (2011), according to him, the definition of a smartphone is a cellular phone using various services such as memory, screen, microprocessor, and modem. So that the features in this smartphone feel more complete compared to other mobile features.

\section{Types of Smartphones}

Smartphones can be divided into:

a. Based on the operating system

An operating system is a system that controls smartphone performance so that users and devices are connected other. The operating system on a smartphone is also called a mobile operating system or Mobile OS. Based on the operating system, the workings of the smartphone operating system include:

1) Presents a graphical interface that allows users to access applications that are already installed on the device.

2) Adjust the layout of the application icon.

3) Manage telephone access.

4) Manage cellular and wireless network connectivity.

When we flashback to the back, the smartphone was first released in 1993 and given the name IBM Simon. But for the new operating system released in 1996 by Palm Inc. and named Palm OS. Although now the Palm OS is not used anymore, since the release of it, began to emerge another operating system that supports the development of mobile phones to date.

Here are some of the names of the most popular operating systems used by smartphone companies:

\section{1) Apple iOS}

Apple iOS is only owned and developed by Apple Inc. Aside from the Apple brand; no other smartphone can use this operating system.

\section{2) Android}

The Android operating system is the most widely used by various smartphone brands, including Samsung, Asus, Xiaomi, Lenovo, etc. In Indonesia alone, Android is more popular compared to other operating systems. Android is a Linux-based operating system developed by Android Inc. and later bought by Google Inc. in 2005. The Android logo is a green robot which means that a smartphone with an Android operating system can modify its performance to your liking.

\section{3) Blackberry OS}

BlackBerry OS was developed by Research in Motion (RIM) to support BlackBerry devices which are also products of RIM. BlackBerry OS uses a Java-based programming language and is the operating system that first launched push email. 
4) Windows Phone

Windows phone is a Windows Mobile replacement operating system developed by the Microsoft company.

5) Bada

Samsung Electronics, based in Korea, in November 2009 launched a bada operating system that can only be used on Samsung Wave series phones. Bada is the Korean language that has a deep oceanic meaning. Giving the name is intended to show competitors that the operating system is already large, that Samsung bada will bring major changes in market share later on.

6) Symbian OS

Symbian OS is an operating system originally developed by Symbian Ltd. and then bought its shares by Nokia. Before the rise of smartphones, Symbian was the operating system most widely used in smartphone system devices.

b. Based on the form of a Smartphone

Based on the shape, smartphones are divided into:

1) Mobile. Everyone certainly knows the form of a cellphone, which is fit to be held in the hand and flexible to carry anywhere. Some have a direct keypad button and there is also a touch screen.

2) iPhone. Is a designation for Apple's smartphone output. The shape

same as mobile phones in general, but only has a touch screen model with a home button on the bottom centre.

3) Tablet. Shaped wide like a book. The widescreen makes the display of writing, pictures and videos look more clear. Can be equipped with a mini keyboard, if used to operate Microsoft Office.

4) iPad. Is a designation for Apple products in the same shape as a tablet.

5) iPod. Apple output products that look almost the same as the iPhone. But its use is to prioritize entertainment or multimedia, namely for photos, videos and listening to music.

6) Smartwatch. In the form of a watch that is connected to the internet and smartphone. Smartwatch is the latest communication tool that smartphone users have begun to glance at. Besides showing the time, you can access GPS, weather, email, SMS and telephone.

7) iWatch. Is a designation for Apple products that have the same shape and function as a smartwatch. Only can be connected with the iPhone..)

\section{RESEARCH METHODOLOGY}

\subsection{Stages of Problem Formulation}

This stage is the process of formulating the problem and limiting the problem that is studied. This is necessitated to be able to direct researchers better in making applications so that what is done does not go beyond the pre-set limits.

\subsection{Stages of Data Collection}

1. Primary Data

Primary data is data that was first recorded and collected in the research. Primary data (main data) requires direct interaction with security employees within the State Polytechnic of Sriwijaya. The steps taken are through interview techniques. Infield practice, the authors conducted interviews with lecturers and students in the State Polytechnic of Sriwijaya.

\section{Secondary Data}

Secondary data is data collected from existing sources. Here, the authors take data indirectly by finding and studying journal references, books, articles, theories that support and other references relating to the final project.

\subsection{System Design Stages}

The system design used in this study is UML (Unified Modeling Language) which consists of Use Cases, Class Diagrams, Activity Diagrams, and Sequence Diagrams. The UML Activity Diagram (AD) is an important diagram for modelling the dynamic aspects of a system [5]. Following the Petri nets semantics, the UML ADs use Petri nets concepts such as places, tokens, and control flows [6].

\section{FIGURES AND TABLES}

\section{RESULT AND DISCUSSION}

\subsection{System Design}

\subsubsection{Usecase Diagram}

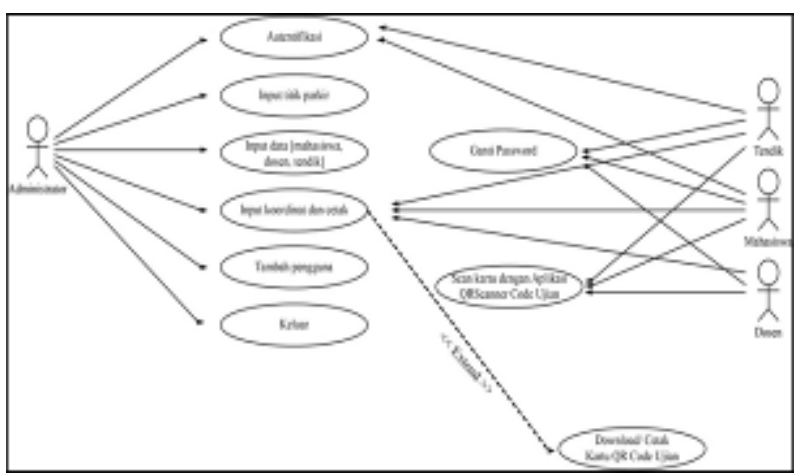

Figure 1. Usecase Diagram 


\subsubsection{Class Diagram}

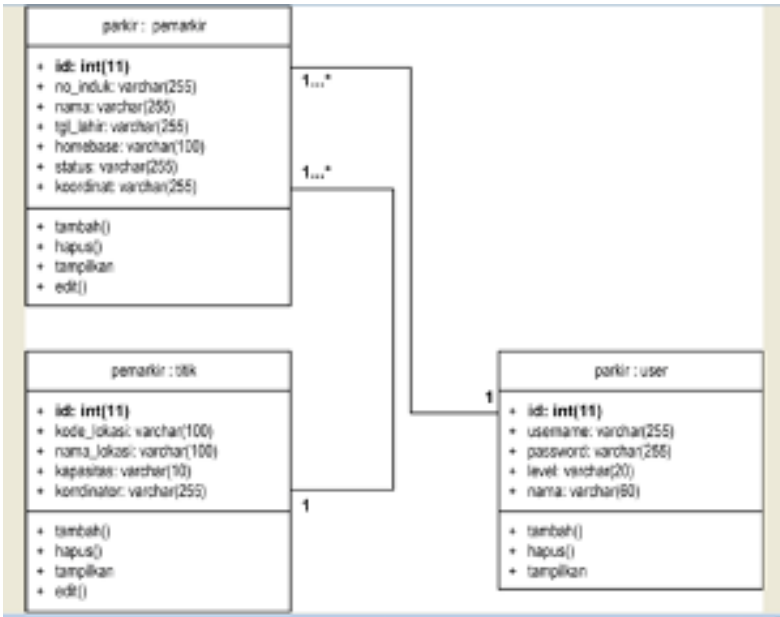

Figure 2. Class Diagram

\subsection{Implementation}

The output of the Application of Campus Parking Area for State Polytechnic of Sriwijaya Based on Smartphone consists of 9 menus namely login, dashboard menu, lecturer data menu, student data menu, educational staff data menu, user data menu, insert coordinate menu, print preview menu, print input menu.

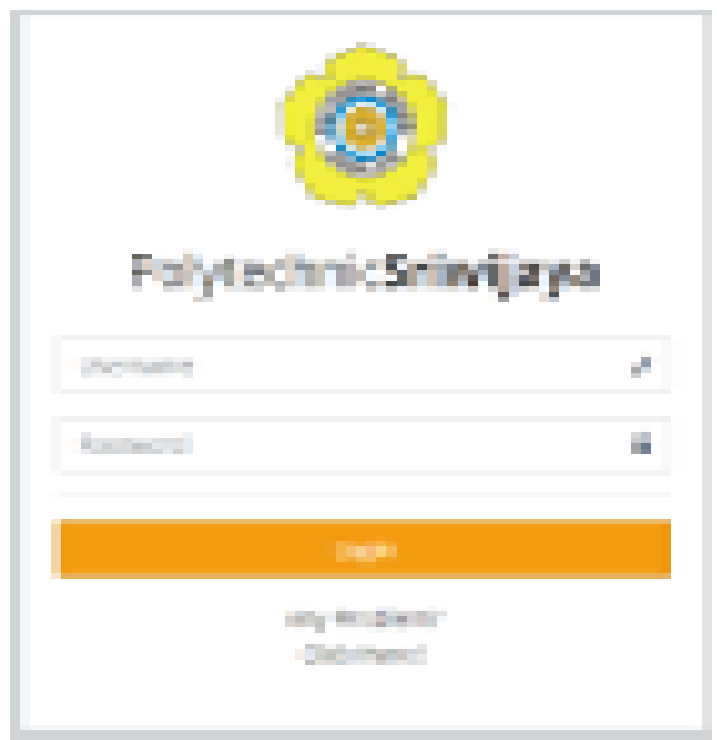

Figure 3. Login

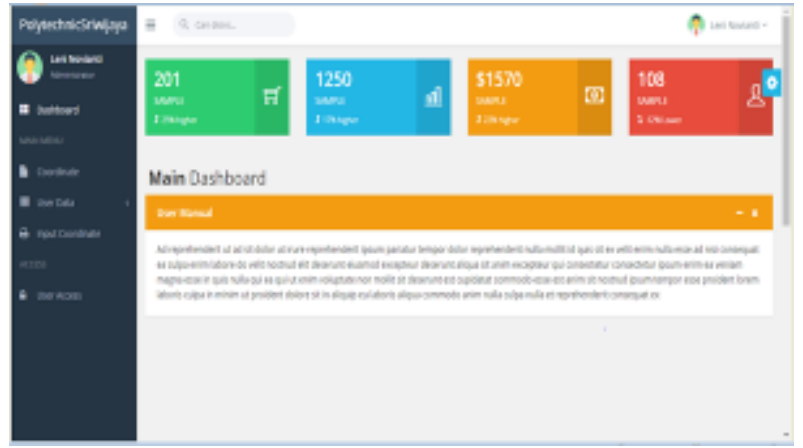

Figure 4. Main dashboard
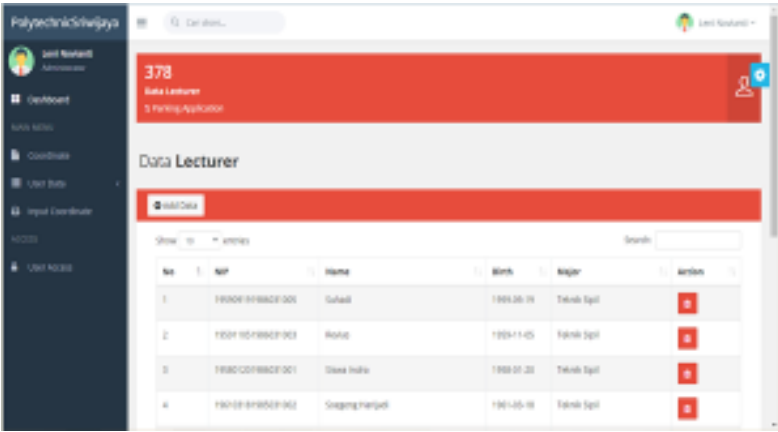

Figure 5. Lecturers Data Menu
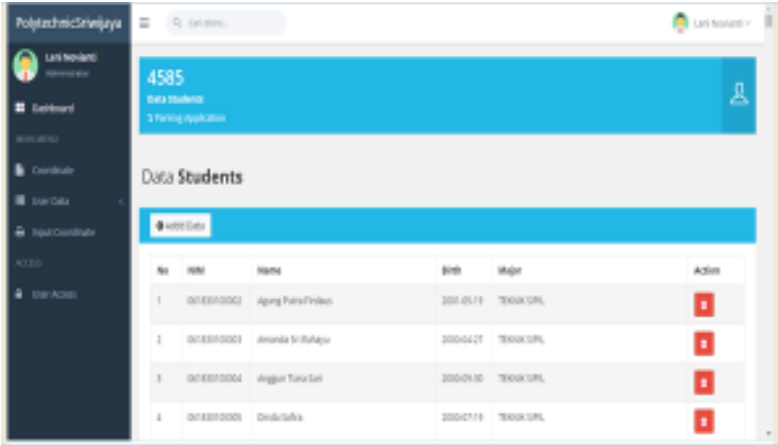

Figure 6. Students Data Menu
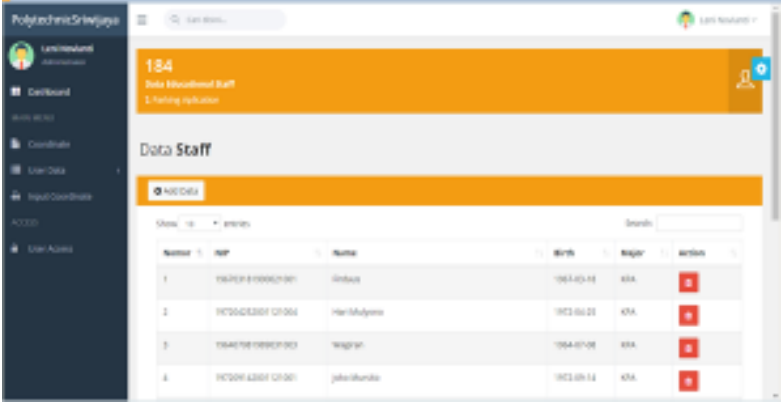

Figure 7. Educational Staff Data Menu

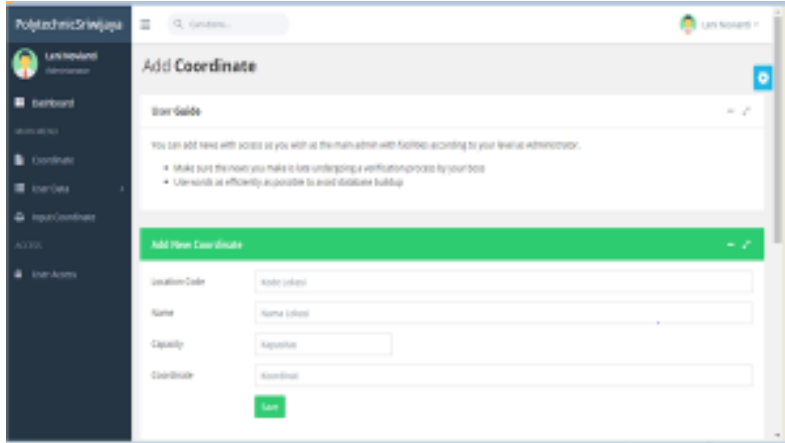

Figure 8. Insert Coordinate Menu 


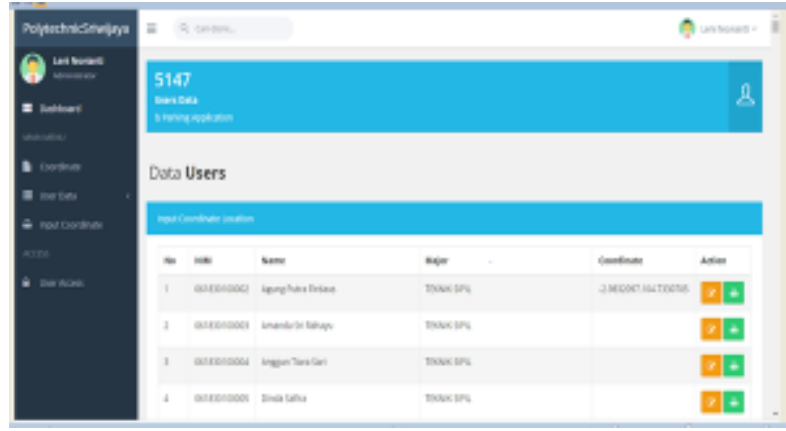

Figure 9. User Data Menu

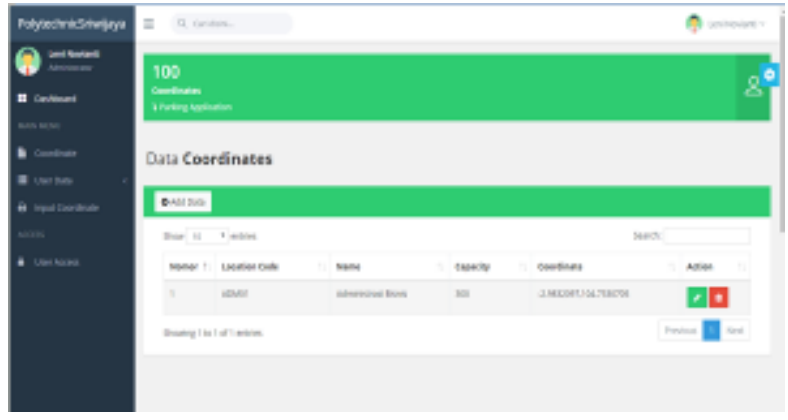

Figure 10. Data Coordinate Menu

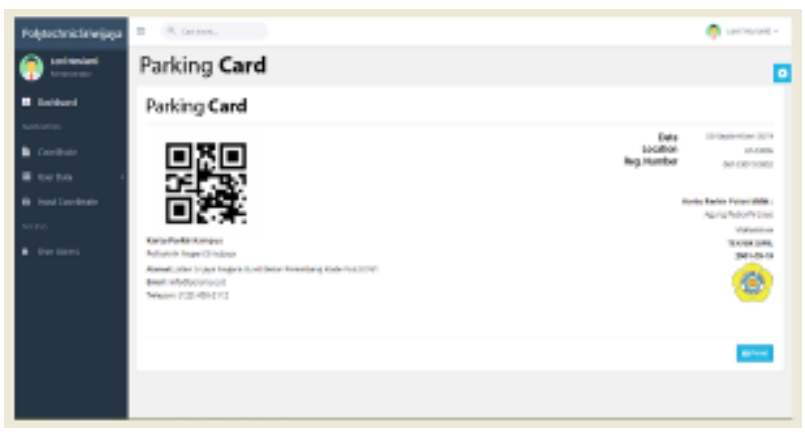

Figure 11. Print Preview Menu

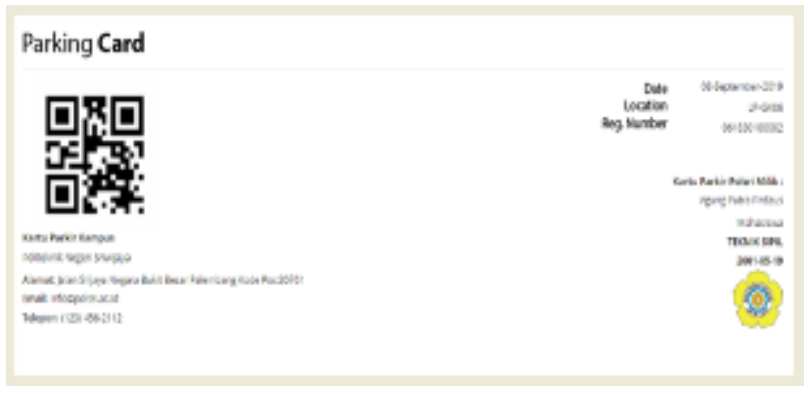

Figure 12. The output of Parking Card.

\section{CONCLUSIONS}

The results of the discussion can be concluded that:

1. Parking Application for the State Polytechnic of Sriwijaya (POLSRI) Based on the smartphone provides information about the availability of parking Area at the State Polytechnic of Sriwijaya (POLSRI) Palembang.

2. Parking Application for State Polytechnic of Sriwijaya (POLSRI) Smartphone-based consists of 8 menus namely dashboard menu, lecturer data menu, student data menu, staffs data menu, inset coordinate menu, print preview menu and print input menu.

3. Parking Application for State Polytechnic of Sriwijaya (POLSRI) Based on Android Smartphone is built using Unified Modeling Language (UML) and using PHP programming language.

\section{REFERENCES}

[1] Anthony Filipovitch and Emmanuel Frimpoang BoamahB. A systems model for achieving optimum parking efficiency on campus: The case of Minnesota State University. TransportPolicy 45 (2016) 86-98. ScienceDirect. Elsevier.

[2] Luigi dell'Olio, Ruben Cordera*, Angel Ibeas, Rosa Barreda, Borja Alonso, Jose Luis Moura. A methodology based on parking policy to promote sustainable mobility in college campuses . Transport Policy. ScienceDirect. Elsevier.

[3] J.-G. Krieg, G. Jakllari, H. Toma, A.-L. Beylot. Unlocking the smartphone's sensors for smart city parking, Pervasive and Mobile Computing (2017). https://doi.org/10.1016/j.pmcj.2017.12.002.

[4] Shoup, D.,2008.The politics and economics of parking on campus In: Stephen Ison, Rye, Tom (Eds.), Transport Demand Management Measures: An International Perspective, pp.121-1492008

[5] OMG, Unified Modeling Language v2.5, http://www.omg.org/spec/UML/2.5/, retrieved: August 2016

[6] H. Störrle, Semantics and verification of data flow in UML 2.0 activities, Electron. Notes Theor. Comput. Sci. 127 (4) (2005) 35-52.

[7] www.oxforddictionaries.com, access 21 Sept 2019

[8] www.businessdictionary.com. Access 15 Agust 2019 